\title{
Flower vs. Leaf Feeding by Pieris brassicae: Glucosinolate-Rich Flower Tissues are Preferred and Sustain Higher Growth Rate
}

\author{
R. C. Smallegange • J. J. A. van Loon • S. E. Blatt • \\ J. A. Harvey • N. Agerbirk • M. Dicke
}

Received: 29 January 2007 / Revised: 3 July 2007 / Accepted: 8 August 2007 /

Published online: 8 September 2007

(C) Springer Science + Business Media, LLC 2007

\begin{abstract}
Interactions between butterflies and caterpillars in the genus Pieris and plants in the family Brassicaceae are among the best explored in the field of insect-plant biology. However, we report here for the first time that Pieris brassicae, commonly assumed to be a typical folivore, actually prefers to feed on flowers of three Brassica nigra genotypes rather than on their leaves. First- and second-instar caterpillars were observed to feed primarily on leaves, whereas late second and early third instars migrated via the small leaves of the flower branches to the flower buds and flowers. Once flower feeding began, no further leaf feeding was observed. We investigated growth rates of caterpillars having access exclusively to either leaves of flowering plants or flowers. In addition, we analyzed glucosinolate concentrations in leaves and flowers. Late-second- and early-third-instar P. brassicae caterpillars moved upward into the inflorescences of B. nigra and fed on buds and flowers until the end of the final (fifth) instar, after which they entered into the wandering stage, leaving the plant in search of a pupation site. Flower feeding sustained a significantly higher growth rate than leaf feeding. Flowers contained levels of glucosinolates up to five times higher than those of leaves. Five glucosinolates were identified: the aliphatic sinigrin, the aromatic phenyethylglucosinolate, and three indole glucosinolates: glucobrassicin, 4-methoxyglucobrassicin, and 4-hydroxyglucobrassicin. Tissue type and genotype were the most important factors affecting levels of identified glucosinolates. Sinigrin was by far the most abundant compound in all
\end{abstract}

R. C. Smallegange $\cdot$ J. J. A. van Loon $(\bowtie) \cdot$ S. E. Blatt $\cdot$ M. Dicke

Laboratory of Entomology, Wageningen University, P.O. Box 8031, 6700 EH Wageningen,

The Netherlands

e-mail: joop.vanloon@wur.nl

J. A. Harvey

Department of Multitrophic Interactions, Netherlands Institute of Ecology, P.O. Box 40, 6666 ZG Heteren, The Netherlands

S. E. Blatt

Chemistry Department, Acadia University, Wolfville, Nova Scotia B4P 2R6, Canada

N. Agerbirk

Department of Natural Sciences, University of Copenhagen, Thorvaldsensvej 40, 1871 Frederiksberg C, Denmark 
three genotypes. Sinigrin, 4-hydroxyglucobrassicin, and phenylethylglucosinolate were present at significantly higher levels in flowers than in leaves. In response to caterpillar feeding, sinigrin levels in both leaves and flowers were significantly higher than in undamaged plants, whereas 4-hydroxyglucobrassicin leaf levels were lower. Our results show that feeding on flower tissues, containing higher concentrations of glucosinolates, provides $P$. brassicae with a nutritional benefit in terms of higher growth rate. This preference appears to be in contrast to published negative effects of volatile glucosinolate breakdown products on the closely related Pieris rapae.

Keywords Herbivory $\cdot$ Lepidoptera $\cdot$ Pieridae $\cdot$ Myrosinase $\cdot$ Isothiocyanates $\cdot$ Nutrition . Brassica nigra

\section{Introduction}

Most plants are not simply homogeneous resources to herbivorous insects but produce discrete organs with different functions. In addition to the vegetative leaf tissues, plants produce reproductive organs (flowers, seeds) that may exhibit significant differences in levels of both nutrients and defensive secondary metabolites. Specialized guilds of herbivores are known to exploit specific plant structures (Schoonhoven et al. 2005). Flowers and seeds may be attacked by insects that rarely feed on leaf tissues, and vice versa. Other herbivores exhibit more plasticity in food selection and will readily feed on all available parts of the plant. Even the latter herbivore types display some preference for a specific plant structure, presumably as a means of obtaining optimal nutrient intake, limiting competition, or obtaining enemy-free space.

The cabbage white butterflies Pieris brassicae L., Pieris rapae L., and Pieris napi L. are specialized on the plant family Brassicaceae. Interactions between these butterflies and their host plants have been explored in detail, and they have acquired the status of a model system in the field of insect-plant biology (Feltwell 1982; Chew and Renwick 1995; Renwick 2002). Glucosinolates, characteristic of the Brassicaceae, play a crucial role as chemical mediators of these interactions. Adult females of P. brassicae and P. rapae, as well as their larvae, exploit glucosinolates as token stimuli during selection of host plants for oviposition and feeding (Renwick et al. 1992; van Loon et al. 1992; Moyes et al. 2000; Schoonhoven and van Loon 2002). The majority of Pieris-Brassica interaction studies has focused on cultivated forms of Brassica oleracea L., which are biennials. Other wild crucifers, such as the annual black mustard, Brassica nigra L. (Koch), are reported to be host plants for P. brassicae in Europe as well (Harvey et al. 2003). We studied within-plant feeding site location in detail on three genotypes of $B$. nigra. We included the analysis of leaf and flower glucosinolates to assess whether a chemical basis for selection of either plant organ in terms of quality or quantity of these compounds could be determined. In addition, we investigated whether growth rates differed between caterpillars feeding on either leaves or flowers to assess whether the observed preference behavior would confer a nutritional benefit.

\section{Methods and Materials}

Plants Seeds of B. nigra var. abyssinica A. Braun from three early flowering accessions were obtained from the Centre for Genetic Resources (CGN, Wageningen, The Netherlands). 
The accessions were: A, CGN06619 (feral population, collected in 1975 from the Peloponesus, Greece); B, Junius CGN06618 (advanced cultivar, collected in 1977 in Germany); and C, Giebra CGN06620 (advanced cultivar, donated in 1965 by the Botanical Garden of the Justus Liebig University, Giessen, Germany). Sowing was done on April 7, 2004 , in a greenhouse at $22 \pm 2{ }^{\circ} \mathrm{C}$ and $60 \pm 5 \% \mathrm{RH}$. Two weeks later, plants were individually transplanted into 1.5-1 pots and transferred to another greenhouse compartment on April 30, 2004. This compartment was kept at $22 \pm 2^{\circ} \mathrm{C}, 60 \% \mathrm{RH}$, natural light supplemented by additional illumination by 500-W SON-T lamps (Philips, Eindhoven, The Netherlands) for $16 \mathrm{hr}$ per day. Flower bud formation and flower opening were recorded daily to determine developmental stage (Harper and Berkenkamp 1975).

Insects Pieris brassicae caterpillars were obtained from a laboratory strain established in 2004 and reared on Brussels sprouts (B. oleracea var. gemmifera cv Cyrus) plants grown in a climatized greenhouse, under the same conditions as given above for $B$. nigra plants. The colony was maintained in a climatized room at $22 \pm 1^{\circ} \mathrm{C}$, RH $40 \pm 5 \%$, and a photoperiod of L16:D8.

Caterpillar Position on the Plant On the first day of an experiment, newly hatched $P$. brassicae larvae were collected from the laboratory culture and taken to the greenhouse. Three caterpillars were placed on the first true leaf below the lowest flowering branch of a plant in growth stage 4.1 (Harper and Berkenkamp 1975). Total numbers of plants used from each accession were A, 8; B, 7; and C, 9. Caterpillar position on the plants was scored each morning in four categories: on a true leaf, on a small leaf in the inflorescence, on a flower, and on the stem. Caterpillar instar stage was recorded daily until the fifth instar was reached. In the late fifth instar, caterpillars that had entered the wandering phase left the plants.

Caterpillar Growth on Leaves and Flowers Three neonate caterpillars were inoculated on each of 20 plants of accession A, on a mature leaf just below the inflorescence. The inoculation took place when plants had just started to flower (growth stage 4.1). Just after caterpillars had molted to the third instar, they were transferred to the lowest branches of the inflorescence on half of the plants. We applied a specially constructed water barrier to prevent caterpillars from migrating from leaves to the inflorescence or vice versa, while not influencing the microclimate around the plant (Fig. 1). Fresh body weights of larvae were determined to the nearest milligram on a Mettler electronic balance at three time points separated by 3 -d intervals.

Preparation of Plant Samples for Glucosinolate Analysis Ten seedlings of each of the three accessions were individually transplanted to $11 / 2-1$ pots. Plants were maintained at $22 \pm 2{ }^{\circ} \mathrm{C}$, RH $60 \pm 5 \%$, during the 16-hr photophase (8 Philips SON-T Agro 400-W sodium lamps) and 8-hr scotophase.

At day 47 after sowing, leaf and flower samples were taken from all 10 plants of each accession. After sampling, five plants of each accession were designated untreated (controls). Three groups of 10 newly hatched P. brassicae caterpillars were placed on three leaves of the five treated plants. As soon as the caterpillars had migrated to the flowers, which took place late in the second or early in the third instar (days 5-6), leaves damaged by the caterpillars were sampled. Leaves of a similar age were sampled from the control plants and intact flowers were sampled from both control and treated plants.

The flower and leaf samples were kept in paper envelopes and stored in a $-20^{\circ} \mathrm{C}$ freezer before and after freeze-drying. Samples were freeze-dried in the envelopes for $2 \mathrm{~d}$ (Labconco Freedry system). After freeze-drying, the envelopes were sealed in plastic and sent to the laboratory of NA in Denmark for chemical analysis. 


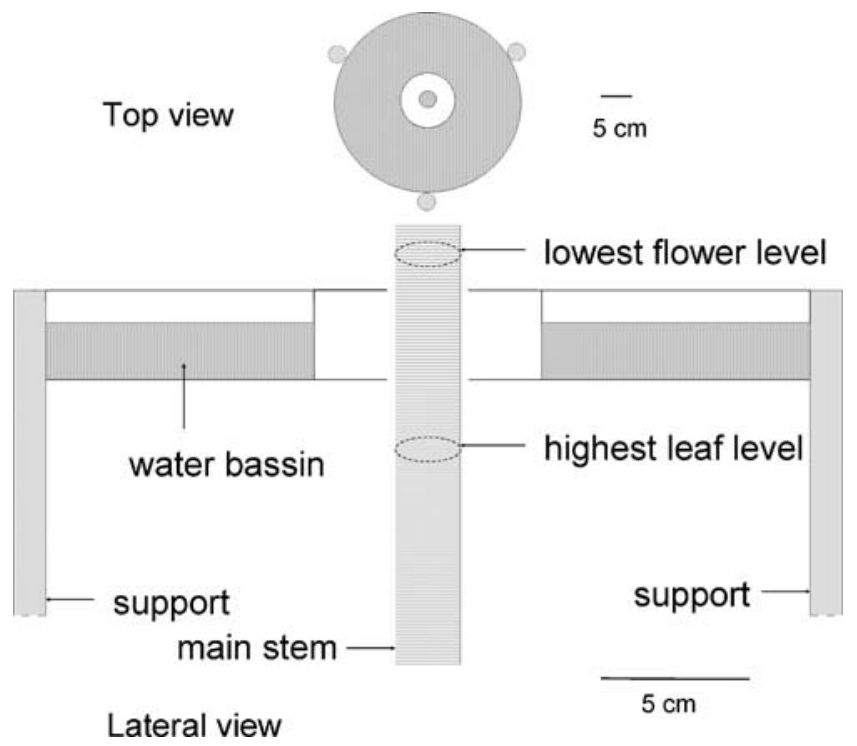

Fig. 1 Schematic drawing (top and lateral views) and dimensions of water barrier applied around the stem of B. nigra plants to prevent movement of caterpillars from leaves to flowers and vice versa. A circular water container was manufactured of plastic. The middle circle consisted of a central platform, preventing drowning of caterpillars feeding on the inflorescence in the rare events of falling down or downward migration. In the center of the platform, a hole allowed the main stem to grow through. The platform was put in place around the main stem just below the branch carrying the first flower buds. The circular opening between the central hole and the stem was blocked with soft foam (not drawn)

Determination of Glucosinolate Content Freeze-dried samples were weighed accurately into 10-ml centrifuge tubes (excluding the petiole part of leaves). For samples below $300 \mathrm{mg}$, the entire sample [27-257 mg dry weight (DW)] was used to avoid errors associated with subsampling, but from a few samples above $300 \mathrm{mg}$, a representative subsample was taken. Each sample was extracted $3 \times$ in $70 \%$ boiling aq. methanol with benzylglucosinolate as internal standard. The combined extracts were adjusted to $10.00 \mathrm{ml}$, of which an amount was applied to an anion exchange column (Agerbirk et al. 2001a). To keep within the linear range of the additional sample preparation steps, the amount of crude extract applied depended on the weight of the sample extracted as follows (DW extracted/ volume applied): $25-75 \mathrm{mg} / 8 \mathrm{ml}, 75-150 \mathrm{mg} / 4 \mathrm{ml}$, and $150-300 \mathrm{mg} / 2 \mathrm{ml}$. Glucosinolates were converted to desulfoglucosinolates (Agerbirk et al. 2007), which were eluted and quantified by high-performance liquid chromatography (HPLC) (Agerbirk et al. 2001a) and identified by comparison of retention times and diode array UV spectra with those of authentic standards (Agerbirk et al. 2001b). A number of unidentified trace peaks with areas typically less than $0.2 \%$ of the desulfosinigrin area were ignored. Generally accepted relative response factors were used for calculation of glucosinolate levels based on the HPLC peak areas (at $229 \mathrm{~nm}$, band width $8 \mathrm{~nm}$ ) of the desulfoderivatives (Wathelet et al. 2004). The recoveries of internal standard in the three extraction series were [mean (SD)] 99\% (6\%), 97\% (13\%), and 98\% (4\%), as compared to HPLC peak areas obtained after application of the internal standard only to DEAE columns in parallel control experiments. Preliminary experiments without the addition of internal standard (comprising both leaf and flower samples from plants both with and without caterpillars feeding) confirmed the absence of benzylglucosinolate as an endogenous glucosinolate in the material, in 
accordance with previous reports (Feeny and Rosenberry 1982; Sang et al. 1984), allowing the use of this glucosinolate as internal standard. The identities of all desulfoglucosinolate peaks were confirmed by liquid chromatograph mass spectrometry (LC-MS) of representative samples with an Agilent 1100 Series LC (Agilent Technologies, Waldbronn, Germany) coupled to a Bruker Esquire 3000+ ion trap mass spectrometer (Bruker Daltonics, Bremen, Germany). An XTerra MS C18 column (Waters, Milford, MA, USA;

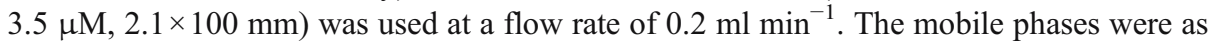
follows: A, $0.1 \%(\mathrm{v} / \mathrm{v}) \mathrm{HCOOH}$ and $50 \mu \mathrm{M} \mathrm{NaCl}$; B, $0.1 \%(\mathrm{v} / \mathrm{v}) \mathrm{HCOOH}$ and $80 \%(\mathrm{v} / \mathrm{v})$ $\mathrm{MeCN}$. The gradient program was 0 to $4 \mathrm{~min}$, isocratic $2 \%(\mathrm{v} / \mathrm{v}) \mathrm{B} ; 4$ to $10 \mathrm{~min}$, linear gradient 2 to $8 \% \mathrm{~B} ; 10$ to $30 \mathrm{~min}$, linear gradient $8 \%$ to $50 \%(\mathrm{v} / \mathrm{v}) \mathrm{B} ; 30$ to $35 \mathrm{~min}$, linear gradient 50 to $100 \%(\mathrm{v} / \mathrm{v}) \mathrm{B} ; 35$ to $40 \mathrm{~min}$, isocratic $100 \% \mathrm{~B}$. The mass spectrometer was run in electrospray mode, observing positive ions. Mass spectral data were treated with the native DataAnalysis software.

The extraction procedure was somewhat simplified compared to the standard protocol (Agerbirk et al. 2001a, originally optimized for seed extraction), as variable sample weights were accepted, and mechanical homogenization during extraction was avoided. These simplifications were justified by results of initial control experiments: A number of both leaf and flower samples of varying weights (up to $400 \mathrm{mg}$ ) were first subjected to the extraction described above. Then, the residue was further extracted for another three times, but this time with mechanical homogenization. In all cases, low relative amounts of glucosinolates (1-16\% compared to the first extract) were detected in the extract obtained with mechanical homogenization (with a tendency for increasing percentage with increasing sample weight). Proportional amounts of internal standard were similarly recovered in all the extracts obtained with mechanical homogenization, showing that the internal standard had already been completely mixed with endogenous analytes during the extraction without homogenization. Hence, it was concluded that the ratio of internal standard to endogenous glucosinolates extracted without mechanical homogenization was representative of their initial concentrations.

Statistical Analyses Proportion of days caterpillars spent on different positions on the plant was treated as binomial data. Distributions over the four positions were compared by using the Kolmogorov-Smirnoff test (GenStat release 8.11; Anonymous 2005). Caterpillar weights were analyzed by analysis of variance. The amount ( $\mu \mathrm{mol} / \mathrm{g} \mathrm{DW})$ of each glucosinolate detected in the leaf and flower samples were analyzed with a generalized linear model after a logarithmic transformation. The effect of time (before and during caterpillar feeding), treatment (undamaged and damaged by caterpillars), plant tissue (leaf and flower), and genotype (accessions) and all possible two- and three-way interactions were investigated (GenStat release 8.11).

\section{Results}

Position on the Plant First and second instars fed primarily on leaves, whereas third instars migrated via the small leaves of the flower branches to the flower buds and flowers. Once flower feeding began, no further leaf feeding was observed (Fig. 2). The distribution of caterpillars over the four positions was statistically similar for the three genotypes (Kolmogorov-Smirnoff test, $P>0.05$ ).

Caterpillars fed in discrete meals two to three times each hour, interspersed with phases without feeding. On a leaf, after termination of a meal, they moved away from the freshly 

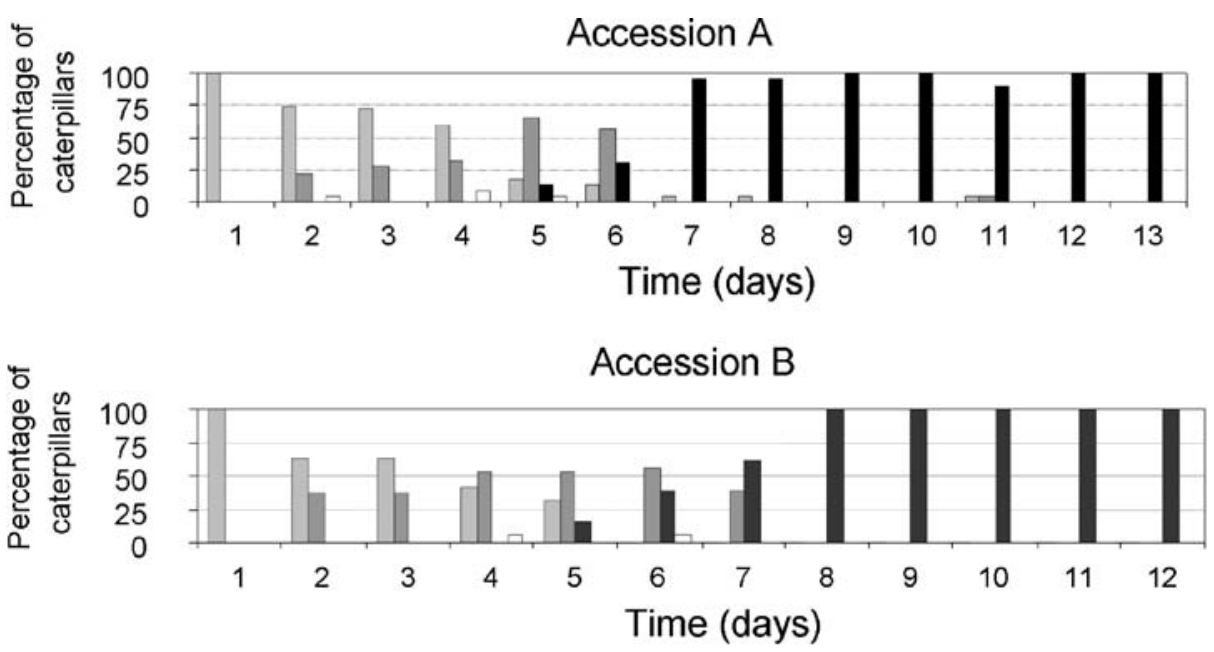

Accession C
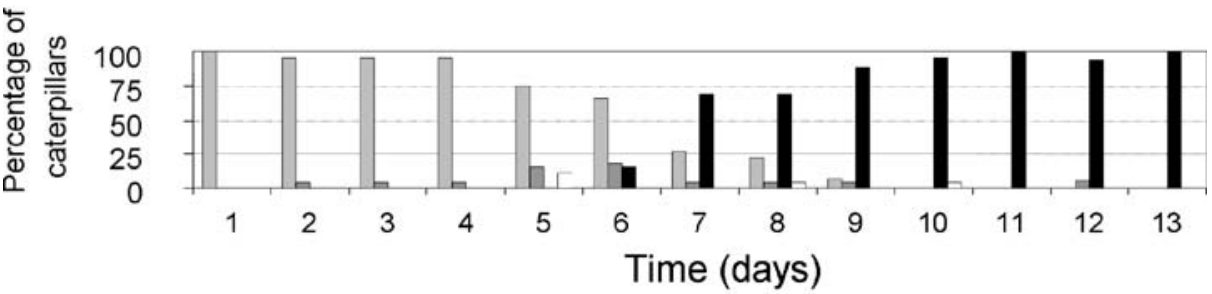

$\square$ on true leaf $\square$ on small leaf $\square$ in flower $\square$ on stem

Fig. 2 Frequency distribution of caterpillar position on B. nigra plants observed daily over a period of 12$13 \mathrm{~d}$. On day 1, neonates were introduced on a true leaf just below the inflorescence. Four organ positions were distinguished: on a true leaf, on a small leaf in the inflorescence, on a flower, or on a stem in the inflorescence. Percentages are averaged based on three caterpillars per plant for eight, seven, and nine plants of accessions $\mathrm{A}, \mathrm{B}$, and $\mathrm{C}$, respectively

damaged wound, after which they rested most of the time elsewhere on the leaf until they moved back to the feeding site. By contrast, in the inflorescence, during a single meal, caterpillars moved from flower to flower along flowering branches. A fifth-instar caterpillar consumed on average $135 \pm 21$ buds and flowers. When they were not feeding, P. brassicae larvae rested on stems immediately adjacent to the flowers.

Caterpillar Growth Caterpillars feeding on flowers of accession A since molting to the third instar had significantly higher fresh body weights on each of the three measuring points (mid-L4 and early and mid-L5 and late L5; Fig. 3) than those that were confined to leaves $(P<0.01$, generalized linear model).

Glucosinolate Levels Five glucosinolates were identified: the aliphatic allylglucosinolate (sinigrin), which occurred in large amounts, and low levels of four aromatic glucosinolates including 2-phenylethylglucosinolate and the three indole glucosinolates indol-3-ylmethylglucosinolate (glucobrassicin), 4-methoxyglucobrassicin, and 4-hydroxyglucobrassicin. Despite the minor levels of the identified aromatic glucosinolates, they were quantified 


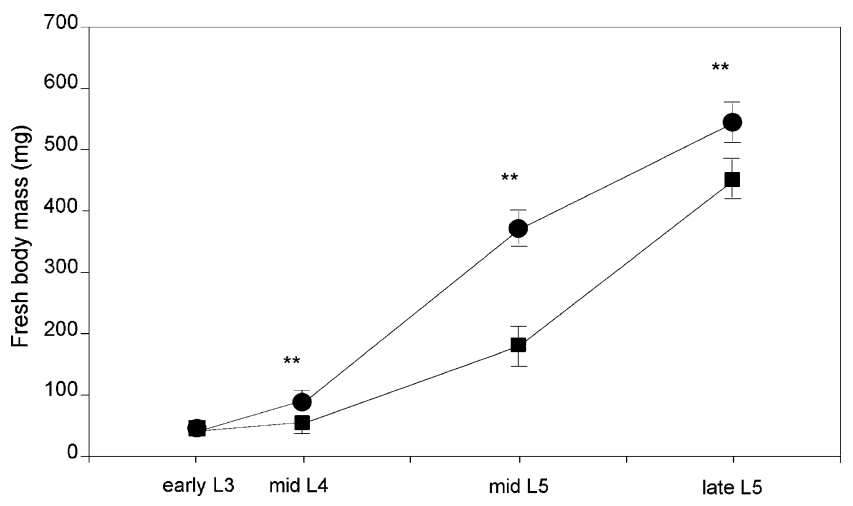

Fig. 3 Fresh body mass of P. brassicae on either flowers (circles) or leaves (squares) of B. nigra in midfourth, mid-fifth, and late-fifth instar developing on B. nigra, accession A. Mean and SEM are plotted for 30 caterpillars

and included in the statistical analyses because of their well established chemosensory influences on Pieris species (Schoonhoven and van Loon 2002). No other significant peaks were detected. 2-Phenylethylglucosinolate was either below the detection limit in leaves (accession C) or present at very low levels (range $0.001-0.013 \mu \mathrm{mol} / \mathrm{g} \mathrm{DW}$ ). We carefully distinguished the peak with the exact retention time of (desulfo) 2-phenylethylglucosinolate from an unidentified trace peak that was more intense in leaf chromatograms (estimated levels $0.03-0.35 \mu \mathrm{mol} / \mathrm{g}$ DW in leaves, $0.01-0.08 \mu \mathrm{mol} / \mathrm{g}$ DW in flowers), that had a retention time $0.7 \mathrm{~min}$ longer than that of (desulfo) 2-phenylethylglucosinolate, and that did not coelute with the authentic standard of 2-phenylethylglucosinolate after spiking.

Genotype and tissue type were the most important factors affecting the levels of identified glucosinolates, and these factors showed a significant interaction (Table 1). No significant interactions were found between treatment and tissue $(P>0.05$ for all glucosinolates). Glucosinolate concentrations have been graphically depicted for accession A in Fig. 4. Sinigrin was by far the most abundant compound in all three genotypes, with levels at least 44 times higher (range 44-305) in leaves and at least 87 times higher (range

Table 1 Results from generalized linear model analysis on log-transformed data of glucosinolate concentrations in two tissue types (leaves and flowers) for three genotypes of $B$. nigra

\begin{tabular}{llllll}
\hline Factor & Sinigrin & PE & GB & 4 OHGB & 4 MeOGB \\
\hline Time & ns & ns & ns & $* * *$ & ns \\
Tissue & $* * *$ & $* * *$ & ns & $* * *$ & ns \\
Treatment & $*$ & ns & ns & $*$ & $n s$ \\
Genotype & $* * *$ & $* * *$ & $* * *$ & $* * *$ & $\mathrm{~ns}$ \\
Tissue $\times$ genotype & $* *$ & $* * *$ & $\mathrm{~ns}$ & $*$ & $\mathrm{~ns}$
\end{tabular}

Treatment means presence or absence of third-instar caterpillars feeding on flowers during $4 \mathrm{~d}$. Effect of the factor "time" refers to changes over $4 \mathrm{~d}$ in intact plants

$\mathrm{PE}=$ phenyethylglucosinolate; $\mathrm{GB}=$ glucobrassicin; $4 \mathrm{OHGB}=4$-hydroxyglucobrassicin; $4 \mathrm{MeOGB}=4$ methoxyglucobrassicin

${ }^{*} P<0.05 ; * * P<0.01 ; * * * P<0.001$ 

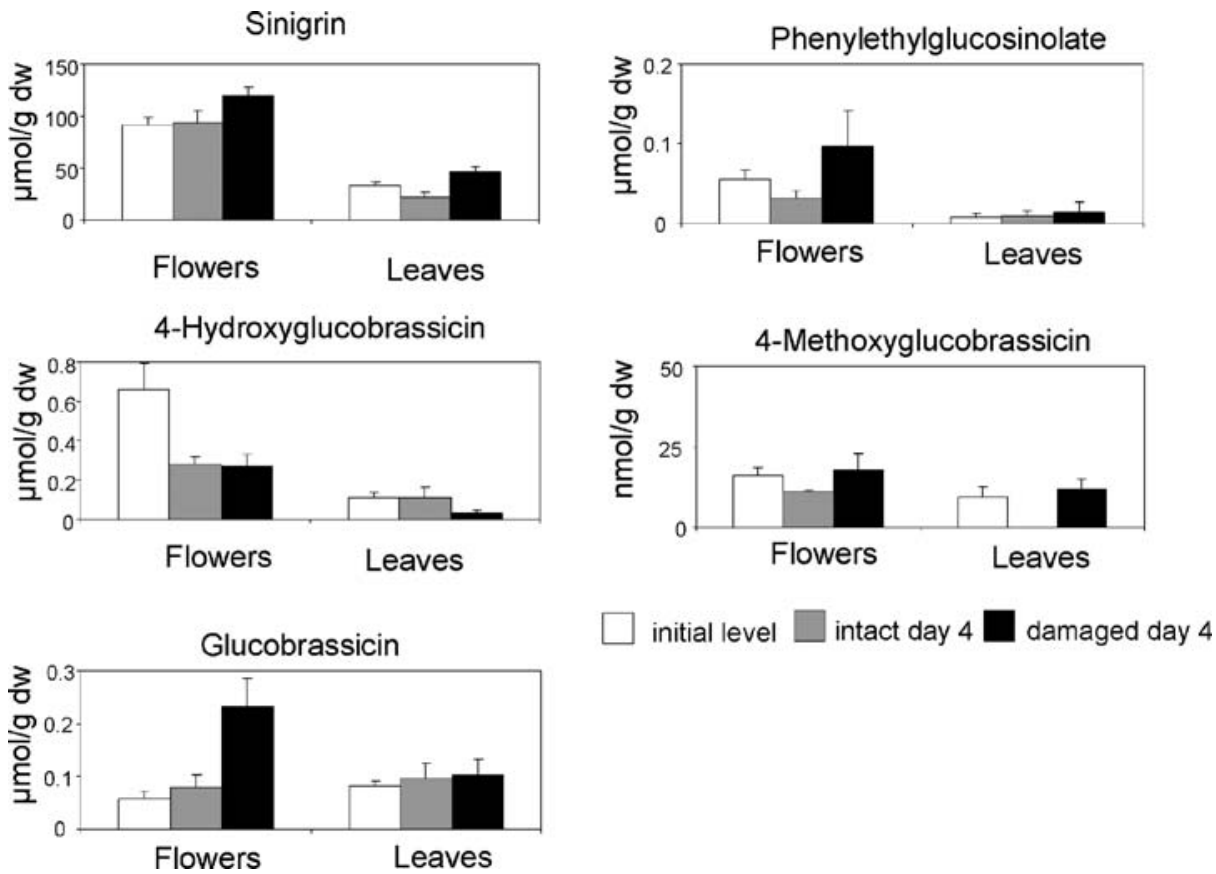

Fig. 4 Concentrations of five glucosinolates (mean + SEM) in leaves and flowers of 10 plants of accession A. For both leaves and flowers, the initial concentration just before treatment, the concentration in leaves or flowers of plants damaged by feeding caterpillars during $4 \mathrm{~d}$, and the concentration determined in leaves or flowers of intact plants $4 \mathrm{~d}$ after caterpillars were introduced on the treated plants

87-447) in flowers of any of the three genotypes and treatments than the second most abundant compound, 4-hydroxyglucobrassicin. Sinigrin, 4-hydroxyglucobrassicin, and phenylethylglucosinolate were present at significantly higher levels in flowers than in leaves. Sinigrin levels were ca. fivefold higher in flowers than in leaves. In response to caterpillar feeding, sinigrin levels in leaves were higher than in undamaged plants $(P<0.05$; Table 1). In flowers of accession A (Fig. 4), there was a similar tendency for induction of sinigrin by caterpillar feeding, but such induction was not seen with flowers from the other two genotypes (results not shown). Levels of other glucosinolates showed moderate variations that were not affected by the experimental variables (Table 1, Fig. 4 and results not shown). There was no systematic induction of any indole glucosinolate or of total indole glucosinolates in response to caterpillar feeding (results not shown).

\section{Discussion}

Our data show that $P$. brassicae third, fourth, and fifth instars preferentially feed on $B$. nigra flowers. Preference was absolute: although leaf material was available in surplus, caterpillars fed exclusively on flowers. Historically, P. brassicae has been commonly considered a folivore (Feltwell 1982), with its impact on plants examined primarily from this perspective. To the best of our knowledge, this is the first detailed study showing that $P$. brassicae larvae preferentially feed on the buds and flowers of its host plant. The status of 
P. brassicae as an agricultural pest has invariably resulted in a focus on cultivated, biennial forms of $B$. oleracea in studies of its host plant relationships. We also observed flower and silique feeding under field conditions (Smallegange et al., unpublished results).

The impact of folivores on plants has both direct and indirect effects. Directly, these herbivores reduce the leaf area available for photosynthesis, thereby decreasing the plants' ability to garner resources for defense and reproduction (Marquis 1984; Mothershead and Marquis 2000; Schoonhoven et al. 2005). Indirectly, leaf herbivory can delay flowering (Meyer and Root 1993; Strauss et al. 1996) or can alter developing flowers both physically (Strauss et al. 1996; Lehtilä and Strauss 1999; Mothershead and Marquis 2000) and chemically (Lohman et al. 1996; Karban and Baldwin 1997). This may cause a reduction in plant attractiveness to pollinators or in the efficiency of pollen delivery, resulting in decreased pollination and, subsequently, reduction of seed set and overall fitness of the plant. Florivory, feeding on flowers, has received less attention than folivory or feeding on other vegetative plant parts despite its common occurrence and potentially high impact on plant fitness (recently reviewed by McCall and Irwin 2006). Feeding on flowers causes damage to structures essential for plant reproductive output (Juenger and Bergelson 1997; Adler et al. 2001). Indirectly, petal damage leads to a reduction in pollinator visitation that not only reduces reproductive success but also affects male fitness (via pollen removal) of the plant as well (Karban and Strauss 1993; Krupnick and Weis 1998; Adler et al. 2001). However, the compensatory abilities of plants can partially overcome the impact of floral herbivory (Hendrix 1988; Krupnick and Weis 1998). Removal of reproductive organs as a preferred mode of feeding has evolutionary consequences, as this type of attack is likely to exert a stronger selection pressure than leaf feeding, especially in annual species like $B$. nigra. Although many plant species accumulate higher concentrations of defensive secondary metabolites in reproductive organs than in vegetative organs (Schoonhoven et al. 2005), in B. nigra, these higher levels are not sufficient to deter the specialist feeder $P$. brassicae. A putative barrier to florivory by generalist herbivores lies in the higher quantities of secondary plant compounds that are typically found in these organs relative to the levels reported for leaves (Rask et al. 2000; Fahey et al. 2001; Brown et al. 2003; Strauss et al. 2004; this study). The location of high concentrations of defensive secondary plant compounds, including glucosinolates, in reproductive structures is consistent with the optimal distribution of chemical defenses predicted by plant defense theory (Zangerl and Bazzaz 1992; van Dam et al. 1996; Wallace and Eigenbrode 2002; Strauss et al. 2004). Myrosinases, $\beta$-thioglucosidase enzymes that convert glucosinolates into products such as isothiocyanates and nitriles, which are volatile in the case of, e.g., sinigrin and 2phenylethylglucosinolate, occur in different forms in flowers and leaves (Rask et al. 2000). By using headspace techniques, isothiocyanates and nitriles have been reported from mechanically macerated bud samples of several Brassica species (Tollsten and Bergström 1988). Phenylacetonitrile was detected in headspace samples of intact $B$. rapa L. flowers (Omura et al. 1999). Benzylcyanide was released in significantly higher amounts from Brassica napus L. in midflowering than in bud stage (Jönsson et al. 2005). High levels of isothiocyanates are potentially toxic to both specialist and generalist herbivorous insects (e.g., Li et al. 2000; Agrawal and Kurashige 2003), while even low levels may be detected by specialized sensory receptors and assist specialized herbivores in host plant finding (Renwick et al. 2006).

The growth rate we observed for caterpillars feeding on flowers was remarkable. The feeding site preference of L3-L5 caterpillars presents a case of within-plant selective foraging, the adaptive value of which might be the ingestion of higher nutritional content in flowers, known to act as nutrient sinks, compared to leaves. Nutrient acquisition during the 
larval stage can affect pupal survival, longevity, and fecundity of Lepidoptera (Feltwell 1982; Van der Meijden et al. 1984; Metspalu et al. 2003). For example, female pupae of Tyria jacobaeae were significantly larger when caterpillars were reared on leaves and inflorescences of Senecio jacobaea plants than when reared on leaves only. This is advantageous because large pupae have a higher eclosion success, and it may explain why T. jacobaeae females prefer flowering plants for oviposition (Vrieling and de Boer 1999).

Faster growth has often been interpreted as a mortality-reducing factor. It is assumed that by reducing the amount of time that larvae are early instars, when they are most vulnerable to attack by natural enemies, they will experience higher survival (the 'slow-growth-highmortality hypothesis' sensu Clancy and Price 1987; Benrey and Denno 1997). This has been experimentally confirmed under field conditions for the interaction between $P$. rapae feeding on B. oleracea and its predators and parasitoids such as Cladophora glomerata (Loader and Damman 1991; Benrey and Denno 1997). However, for other tritrophic interactions, faster growth was associated with higher mortality due to natural enemies (e.g., Clancy and Price 1987). Biere et al. (2002) found that larvae of the moth Hadena bicruris exhibit a strong preference for seeds of their food plant, Silena latifolia, over leaf tissues. Herbivore development proceeded more rapidly on seeds, and the larvae were less susceptible to parasitism from their main endoparasitoid, Microplitis tristis.

Herbivorous insects specialized on glucosinolate-containing plants typically avoid the formation of toxic isothiocyanates by employing specialized detoxifying mechanisms. In the case of $P$. brassicae, this is accomplished by a nitrile specifier protein (NSP) in the gut that changes the products of the myrosinase-catalysed hydrolysis of glucosinolates from isothiocyanates to relatively harmless nitriles (Wittstock et al. 2004), which may be further metabolized before excretion depending on side chain structure (Agerbirk et al. 2006; 2007). Shortly before this mechanism was reported, it was discovered that allyl isothiocyanate, the volatile hydrolysis product of sinigrin, is toxic to the specialist feeder P. rapae when feeding on an artificial diet (Agrawal and Kurashige 2003). Assuming a 20\% DW in the artificial diet as used by Agrawal and Kurashige (2003), the maximum concentration to which P. rapae caterpillars were exposed in their study was $8.5 \mu \mathrm{mol} / \mathrm{g} \mathrm{DW}$. This dose caused significant negative effects on growth rate and inhibited development. In contrast, sinigrin levels in B. nigra flowers were more than 10 times higher (Fig. 4) and flowers sustained higher growth rates of $P$. brassicae than leaves, which had average levels of sinigrin two times higher than the corresponding amount of allylisothiocyanate as applied in the artificial diet. Assuming that isothiocyanates were produced in significant amounts during ingestion of glucosinolate-containing foliage by $P$. rapae, an involvement of the glucosinolate-myrosinase system in defense against this specialist species was suggested. Brassica nigra plants that had been induced by previous $P$. rapae feeding damage had a $27 \%$ increase in sinigrin concentration, but also 43\% higher trichome density (Traw and Dawson 2002). Our data confirm the reported induction of sinigrin in leaves upon feeding, but also demonstrate that the magnitude of the induction is minor relative to the difference between leaves and flowers. With the elucidation of the NSP-based mechanism for detoxification of the glucosinolatemyrosinase system, the suggested involvement of the glucosinolate-myrosinase system and defense to specialists now needs to be re-evaluated. Formation of isothiocyanates is to be expected only if the myrosinase activity in the plant is so high that available NSP cannot completely direct the reaction towards nitriles, combined with glucosinolate levels sufficiently high to produce toxic levels of isothiocyanates. The selective foraging on flowers by $P$. brassicae documented here demonstrates that the caterpillars are able to detoxify even high levels of sinigrin, such as those present in B. nigra flower tissue. Not only high glucosinolate levels but also high myrosinase activity would be needed to exert toxic effects on Pieris 
caterpillars, as has been experimentally demonstrated for another glucosinolate-adapted herbivorous insect, Plutella xylostella (Li et al. 2000). Glucosinolates occur in cells of all organs of Brassicaceous plants, whereas myrosinases can be found in scattered glucosinolatefree cells. It remains to be examined whether flower buds of different age, flowers, and siliques of $B$. nigra have cells that contain myrosinases. In the related B. napus L., expression of the MYR1-gene coding for particular myrosinase isoforms has been demonstrated to occur in all organs investigated, including petals (Falk et al. 1992), although myrosinase was absent in very young flower buds in this species (Andréasson et al. 2001). Myrosinase gene promoters fused to beta-glucuronidase as a reporter showed expression of myrosinase in idioblast myrosin cells in immature and mature seeds and phloem myrosin cells of B. napus (Thangstad et al. 2004). Data on headspace composition of inflorescences actually fed upon by Pieris spp. are not available. Follow-up studies on the types and quantities of volatile breakdown products emitted by herbivore-damaged flowers are required to quantify myrosinase activity levels in flowers. If these levels are low, the better performance associated with flower feeding might be reconciled with a role of the glucosinolatemyrosinase system in defense against the specialist $P$. brassicae. However, a likely and simple explanation of the better performance associated with flower-feeding may be that the caterpillars are able to efficiently detoxify the glucosinolate-myrosinase defense system in both organs, and that flowers, major nutrient sinks on a plant, are more nutritious than leaves. The fact that early instars did not migrate to flowers may be an adaptation to factors other than nutrient content: leaves are the site of oviposition, are present earlier in the season than flowers, and may provide better refuge from natural enemies for small instars. We have never observed P. brassicae or P. rapae ovipositing on flowers or flowering stems.

Neither $P$. rapae nor $P$. brassicae sequester glucosinolates for their own defense against natural enemies (Müller et al. 2003), in contrast to what had been published earlier by Aplin et al. (1975). The intensely green, clear regurgitant these caterpillars instantly, and typically, produce when attacked may contain highly concentrated glucosinolate hydrolysis products (nitriles) stored in the foregut. Presence of concentrated glucosinolate hydrolysis products may explain the obvious repellent effect of regurgitant to natural enemies such as Cotesia wasps and predators (Brodeur et al. 1996). Consequently, caterpillars may prefer flower tissues that contain high levels of these compounds, thus boosting their defense against both specialist and generalist natural enemies (Soler et al. 2005). Behavioral experiments with parasitoids and predators known to act as common natural enemies of P. brassicae (Feltwell 1982) are required to test this hypothesis.

Acknowledgments The authors thank André Gidding, Frans van Aggelen, and Leo Koopman for rearing $P$. brassicae, Unifarm for sowing and planting B. nigra, and the CGN (Wageningen, The Netherlands) for supplying B. nigra seeds. Matthieu Joosten (Laboratory of Phytopathology, Wageningen University) is acknowledged for freeze-drying the samples. We thank C.E. Olsen for LC-MS analyses and Birgitte B. Rasmussen and Lene K. Petersen for excellent technical assistance. Financial support from Gluds Legat and the Dutch Science Foundation NWO (grant 811.34.006) is gratefully acknowledged.

\section{References}

Adler, L. S., Karban, R., and Strauss, S. Y. 2001. Direct and indirect effects of alkaloids on plant fitness via herbivory and pollination. Ecology 82:2032-2044.

Agerbirk, N., Olsen, C. E., and Nielsen, J. K. 2001a. Seasonal variation in glucosinolates and insect resistance in two types of Barbarea vulgaris ssp. arcuata. Phytochemistry 58:91-100. 
Agerbirk, N., Petersen, B. L., Olsen, C. E., Halkier, B. A., and Nielsen, J. K. 2001b. 1,4Dimethoxyglucobrassicin in Barbarea and 4-hydroxyglucobrassicin in Arabidopsis and Brassica. J. Agric. Food Chem. 49:1502-1507.

Agerbirk, N., Müller, C., Olsen, C. E., and Chew, F. S. 2006. A common pathway for metabolism of 4hydroxybenzylglucosinolate in Pieris and Anthocaris (Lepidoptera: Pieridae). Biochem. Syst. Ecol. 34:189-198.

Agerbirk, N., Olsen, C. E., TopbJerg, H. B., and Sørensen, J. C. 2007. Host plant dependent metabolism of 4-hydroxybenzylglucosinolate in Pieris rapae: substrate specificity and effects of genetic modification and plant nitrile hydratase. Insect Biochem. Mol Biol. in press.

Agrawal, A. A., and Kurashige, N. S. 2003. A role for isothiocyanates in plant resistance against the specialist herbivore Pieris rapae. J. Chem. Ecol. 29:1403-1415.

Andréasson, E., Bolt Jørgensen, L., Höglund, A.-S., RASK, L., and Meijer, J. 2001. Different myrosinase and idioblast distribution in Arabidopsis and Brassica napus. Plant Physiol. 127:1750-1763.

Anonymous, 2005. The Guide to GenStat ${ }^{\circledR}$ Release 8.11. VSN International, Oxford.

APLin, R. T., D'ARCY WARD, R., and RothSChILD, M. 1975. Examination of large and small white butterflies (Pieris spp.) for presence of mustard oils and mustard oil glycosides. J. Entomol. 50:73-78.

BENREY, B., and DENNO, R. F. 1997. The slow-growth-high-mortality hypothesis: a test using the cabbage butterfly. Ecology 78:987-999.

Biere, A., Elzinga, J., Honders, S., and Harvey, J. 2002. A plant pathogen reduces the enemy-free space of an insect herbivore on a shared host plant. Proc. R. Soc. Lond. B Biol. Sci. 269:2197-2204.

Brodeur, J., Geervliet, J. B. F., and Vet, L. E. M. 1996. The role of host species, age and defensive behaviour on ovipositional decisions in a solitary specialist and gregarious generalist parasitoid (Cotesia species). Entomol. Exp. Appl. 81:125-132.

Brown, P. D., Tokuhisa, J. G., Reichelt, M., and Gershenzon, J. 2003. Variation of glucosinolate accumulation among different organs and developmental stages of Arabidopsis thaliana. Phytochemistry 62:471-481.

Chew, F. S., and Renwick, J. A. A. 1995. Chemical ecology of host-plant choice in Pieris butterflies, pp. 214-238, in R. T. Cardé and W. J. Bell (eds.). Chemical Ecology of Insects. Chapman \& Hall, New York.

ClANCY, K. M., and PRICE, P. W. 1987. Rapid herbivore growth enhances enemy attack: sublethal plant defenses remain a paradox. Ecology 68:733-737.

Fahey, J. W., Zalemann, A. T., and Talalay, P. 2001. The chemical diversity and distribution of glucosinolates and isothiocyan ates among plants. Phytochemistry 56:5-51.

Falk, A., Xue, J. P., LenMan, M., and Rask, L. 1992. Sequence of a cDNA clone encoding the enzyme myrosinase and expression of myrosinase in different tissues of Brassica napus. Plant Sci. 83:181-186.

FEeny, P., and Rosenberry, L. 1982. Seasonal variation in the glucosinolate content of North American Brassica nigra and Dentaria species. Biochem. Syst. Ecol. 10:23-32.

Feltwell, J. S. E. 1982. Large White Butterfly, the Biology, Biochemistry and Physiology of Pieris brassicae (Linnaeus). Dr W. Junk, The Hague.

HARPER, F. R., and BERKENKAMP, B. 1975. Revised growth-stage key for Brassica campestris and B. napus. Can. J. Plant Sci. 55:657-658.

HARVEY, J. A., VAN DAM, N. M., and Gols, R. 2003. Interactions over four trophic levels: foodplant quality affects development of a hyperparasitoid as mediated through a herbivore and its primary parasitoid. $J$. Anim. Ecol. 72:520-531.

HENDRIX, S. D. 1988. Herbivory and its impact on plant reproduction, pp. 246-263, in J. L. Doust and L. L. Doust (eds.). Plant Reproductive Ecology: Patterns and Strategies. Oxford University Press, New York.

JÖNSSON, M., LINDKVIST, A., and ANDERSON, P. 2005. Behavioural responses in three ichneumonid pollen beetle parasitoids to volatiles emitted from different phenological stages of oilseed rape. Entomol. Exp. Appl. 115:362-369.

Juenger, T., and Bergelson, J. 1997. Pollen and resource limitation of compensation to herbivory in scalet gilia, Ipomopsis aggregata. Ecology 78:1684-1695.

KARBAN, R., and BALDWIN, I. T. 1997. Induced Responses to Herbivory. Chicago University Press, Chicago.

KARBAN, R., and STRAUSS, S. Y. 1993. Effects of herbivores on growth and reproduction of their perennial host, Erigeron glaucus. Ecology 74:39-46.

KRUPNICK, G. A., and WEIS, A. E. 1998. Floral herbivore effect on the sex expression of an andromonoecious plant, Isomeris arborea (Capparaceae). Plant Ecol. 134:151-162.

LEHTILÄ, K., and STRAUSS, S. Y. 1999. Effects of foliar herbivory on male and female reproductive traits of wild radish, Raphanus raphanistrum. Ecology 80:116-124.

Li, Q., Eigenbrode, S. D., Stringam, G. R., and Thiagarajah, M. R. 2000. Feeding and growth of Plutella xylostella and Spodoptera eridania on Brassica juncea with varying glucosinolate concentrations and myrosinase activities. J. Chem. Ecol. 26:2401-2419. 
LOADER, C., and DAMMAN, H. 1991. Nitrogen content of food plants and vulnerability of $P$. rapae to natural enemies. Ecology 72:1586-1590.

Lohman, D. J., ZANGerL, A. R., and Berenbaum, M. R. 1996. Impact of floral herbivory by parsnip webworm (Oecophoridae: Depressaria pastinacella Dupolnchel) on pollination and fitness of wild parsnip (Apiaceae: Pastinaca sativa L.). Am. Midl. Nat. 136:407-412.

MARQUIS, R. J. 1984. Leaf herbivores decrease fitness of a tropical plant. Science 226:537-539.

MCCALL, A. C., and IRWIN, R. E. 2006. Florivory: the intersection of pollination and herbivory. Ecol. Lett. 9:1351-1365.

Metspalu, L., Hitesaar, K., Joudu, J., and Kuusik, A. 2003. Influence of food on the growth, development and hibernation of the Large White butterfly (Pieris brassicae). Agron. Res. 1:85-92.

MEYER, G. A., and Root, R. B. 1993. Effects of herbivorous insects and soil fertility on reproduction of goldenrod. Ecology 74:1117-1128.

MothersheAd, K., and MARquis, R. J. 2000. Fitness impacts of herbivory through indirect effects on plant-pollinator interactions in Oenothera macrocarpa. Ecology 81:30-40.

Moyes, C. L., Collin, H. A., Britton, G., and Raybould, A. F. 2000. Glucosinolates and differential herbivory in wild populations of Brassica oleracea. J. Chem. Ecol. 26:2633-2641.

MÜLler, C., AgerbiRK, N., and Olsen, C. E. 2003. Lack of sequestration of host plant glucosinolates in Pieris rapae and $P$. brassicae. Chemoecology 13:47-54.

OMURA, H., HONDA, K., and HAYASHI, N. 1999. Chemical and chromatic bases for preferential visiting by the cabbage butterfly, Pieris rapae, to rape flowers. J. Chem. Ecol. 8:1895-1906.

Rask, L., AndrÉasson, E., Ekbom, B., EriKsson, S., Pontoppidan, B., and MeiJer, J. 2000. Myrosinase: gene family evolution and herbivore defense in Brassicaceae. Plant Mol. Biol. 42:93-113.

RENWICK, J. A. A. 2002. The chemical world of crucivores: lures, treats and traps. Entomol. Exp. Appl. 104:35-42.

Renwick, J. A. A., Radke, C. D., Sachdev-Gupta, K., and StÄdler, E. 1992. Leaf surface chemicals stimulating oviposition by Pieris rapae (Lepidoptera: Pieridae) on cabbage. Chemoecology 3:33-38.

Renwick, J. A. A., Haribal, M., GouinguenÉ, S., and StÄDler, E. 2006. Isothiocyanates stimulating oviposition by the diamondback moth, Plutella xylostella. J. Chem. Ecol. 32:755-766.

SANG, J. P., Minchinton, I. R., Johnstone, P. K., and Truscott, R. J. W. 1984. Glucosinolate profiles in the seed, root and leaf tissue of cabbage, mustard, rapeseed, radish and swede. Can. J. Plant Sci. 64:77-92.

SchoONHOVEN, L. M., and VAN LOON, J. J. A. 2002. An inventory of taste in caterpillars: each species its own key. Acta Zool. Acad. Sci. Hung. 48 (Suppl. 1):215-263.

Schoonhoven, L. M., VAn Loon, J. J. A., and Dicke, M. 2005. Insect-Plant Biology. Oxford University Press, Oxford.

Soler, R., Bezemer, T. M., Van Der Putten, W. H., Vet, L. E. M., and Harvey, J. A. 2005. Root herbivore effects on above-ground herbivore parasitoid and hyperparasitoid performance changes in plant quality. J. Anim. Ecol. 74:1121-1130.

StRAuss, S. Y., CONNER, J. K., and RUSH, S. L. 1996. Foliar herbivory affects floral characters and plant attractiveness to pollinators: implications for male and female plant fitness. Am. Nat. 147:1098-1107.

StRauss, S. Y., IRWIN, R. E., and LAmBRIX, V. M. 2004. Optimal defence theory and flower petal colour predict variation in the secondary chemistry of wild radish. J. Ecol. 92:132-141.

Thangstad, O. P., Gilde, B., Chadchawan, S., Seem, M., Husebye, H., Bradley, D., and Bones, A. M. 2004. Cell specific, cross-species expression of myrosinases in Brassica napus, Arabidopsis thaliana and Nicotiana tabacum. Plant Mol. Biol. 54(5):97-611.

TOllsten, L., and BERGSTRÖM, G. 1988. Headspace volatiles of whole plants and macerated plant parts of Brassica and Sinapis. Phytochemistry 27:2073-2077.

TRAW, M. B., and DaWson, T. E. 2002. Reduced performance of two specialist herbivores (Lepidoptera: Pieridae, Coleoptera: Chrysomelidae) on new leaves of damaged black mustard plants. Environ. Entomol. 31:714-722.

Van Dam, N. M., De Jong, T. J., Isawa, Y., and Kubo, T. 1996. Optimal distribution of defences: are plants smart investors? Funct. Ecol. 10:128-136.

Van der Meidden, E., Van Bemmelen, M., Kooi, R., and Post, B. J. 1984. Nutritional quality and chemical defence in the ragwort-cinnabar moth interaction. J. Anim. Ecol. 53:443-453.

Van Loon, J. J. A., Blaakmeer, A., Griepink, F. C., Van Beek, T. A., Schoonhoven, L. M., and De GrooT, Ae. 1992. Leaf surface compound from Brassica oleracea (Cruciferae) induces oviposition by Pieris brassicae (Lepidoptera: Pieridae). Chemoecology 3:39-44.

VRIELING, K., and DE BOER, N. J. 1999. Host-plant choice and larval growth in the cinnabar moth: do pyrrolizidine alkaloids play a role? Entomol. Exp. Appl. 91:251-257.

WALLACE, S. K., and EigenBRODE, S. D. 2002. Changes in the glucosinolate-myrosinase defense system in Brassica juncea cotyledons during seedling development. J. Chem. Ecol. 28:243-256. 
Wathelet, J.-P., Iori, R., Leoni, O., Quinsac, A., and Palmieri, S. 2004. Guidelines for glucosinolate analysis in green tissues used for biofumigation. Agroindustria 3:257-266.

Wittstock, U., Agerbirk, N, Stauber, E. J., Olsen, C. E., Hippler, M., Mitchell-Olds, T., GERShEnZON, J., and Vogel, H. 2004. Successful herbivore attack due to metabolic diversion of a plant chemical defense. Proc. Natl. Acad. Sci. U. S. A. 101:4859-4864.

ZANGerl, A. R., and BAZZAZ, F. A. 1992. Theory and pattern in plant defence allocation, pp. 363-391, in R. S. Fritz and E. L. Simms (eds.). Plant Resistance to Herbivores and Pathogens: Ecology, Evolution and Genetics. University of Chicago Press, Chicago. 